\title{
Cytochemical Studies on G11. vestibulares nasi of Cat
}

By

\author{
Ken Takamura \\ Department of Anatomy, School of Medicine, Keio-Gijuku University, Tokyo \\ (Director: Prof. Dr. T. Tanig u chi)
}

Although histological studies of Gll. vestibulares nasi in several species of mammals were carried out by Ma eda (1953), no cytochemical approach has been made. In the present study, the author has observed Gll. vestibulares nasi of cat cytochemically in the normal state and further the changes caused by the administration of pilocarpine.

\section{Material and Methods}

A $1 \%$ pilocarpine solution was injected subcutaneously at a rate of $0.5 \mathrm{ml}$ per $1 \mathrm{~kg}$ of body weight, into thirty healthy adult cats. These animals were killed in thirty minutes after the administration. The tissues were resected and put into the fixative fluids immediately. Ten of these thirty cats were not treated with pilocarpine, as control animals. The tissues taken from those control animals were also treated in the same way in the following procedures as the injected animals. For general cytological observations, the material was fixed in Levi's solution, and stained with the Heidenhain's iron hematoxylin. For the basophilia examination, the formalin fixed paraffin sections were stained with $1 \%$ aqueous solution of thionin. Polysaccharide was detected by the periodic acid-Schiff's reaction on the alcohol fixed paraffin sections. Alkaline and acid phosphatase reactions were examined by the Gomori's revised methods (Gomori, 1952).

\section{Observations}

Cytology

Control (Figs. 1 and 2)

The terminal portion of the cat Gll. vestibulares nasi is composed 
of glandular cells, myoepithelium and surrouding basement membrane. Though the myoepithelium is usually distinctly seen, looking semilunar and getting into the basal parts of glandular cells, it, sometimes, looks not completely semilunar, when it is ill-developed. The terminal portion of the gland consists of simple columnar or cuboidal cells. The basement membrane is always distinctly demonstrated, even when the development of myoepithelium is incomplete. The nucleus of the glandular cell is situated in the basal part of the cytoplasm. It is globular-shaped and has an eccentric single nucleolus. In the nucleus scattered chromatin granules are present. In the cytoplasm, mitochondria with vague contour are seen running in various directions irregularly. Most of the mitochondria are filamentous and beaded. There are irregular-sized cytoplasmic brown pigment granules in the region between nucleus and the glandular lumen, and in the lateral region from the nucleus. In some places, on the other hand, there are terminal portions, which, lack pigment granules. In the columnar cell, the half of the cytoplasm neighbouring the glandular lumen is stained somewhat more deeply than the opposite half, with iron hematoxylin. There are also numbers of cytoplasmic vacuoles, which are not stained by the iron hematoxylin. Sometimes an unstained space is visible in the region above the nucleus, and it is considered as the negative image of the Golgi bodies. It is impossible to demonstrate mitochondria in the cuboidal cells, in which a few unstained vacuoles are recognized. In both the cuboidal and the columnar cells, any so-called secretory granules are not clearly demonstrated.

\section{Injected animal (Figs. 3 and 4 )}

No appreciable change was observed in the nucleus. Mitochondria are beaded and filamentous as well as those seen in the control material, showing no remarkable change. Number of cells protrude their cytoplasm into the glandular lumen. These protuberances are stained more deeply by the iron hematoxylin than other parts, and their stainability is more intense than that seen in the control preparations. In this terminal extension of cytoplasm, however, no granules are found, which can be ascertained to be the secretion granules. In most of the terminal portions the pigment granules decrease, but in some terminal portions they do not change. The unstained vacuoles show decrease when compared with the picture in the control preparations. 


\section{Basophilia}

Control (Figs. 5 and 6)

The cuboidal cells are stained more deeply than the columnar cells. The cytoplasm is full of beaded filaments, which show reddish-violet metachromasia with thionin. The portion of the cytoplasm neighbouring the upper pole of the nucleus is stained somewhat lightly, and the more peripheral part is stained deeply. Around the nucleus, irregularsized pigment granules are demonstrated, being stained somewhat bluish. Within the cytoplasm a few vacuoles are present, which are not stained by thionin. The nucleus is stained remarkable reddish-violet. The reddish-violet stainability on the columnar cells is weaker than that of the cuboidal cell. The unstained vacuoles are seen abundantly in the cytoplasm between the upper pole of the nucleus and the glandular lumen. The brown pigment granules, which are localized around the nucleus and in the part of the cytoplasm above the nucleus, are stained blue. The beaded filaments in the cytoplasm, which are stained reddishviolet, are probably mitochondria.

The whole myoepithelium except nuclei is stained lightly blue. The basement membrane is hardly stained. The reddish-violet coloured substance, which has been described above, my consist mainly of ribonucleoprotein.

\section{Injected animal (Figs. 7 and 8)}

The unstained vacuoles in the cytoplasm increase. The coloration of the whole field looks lighter. Reddish-violet stained filaments are present among these vacules. Being utterly different from the picture in the control, there are many cells, the basal parts of whose cytoplasm are coloured in vivid reddish-violet. The brown pigment granules, which are stained blue, have decreased. No appreciable stainability is observed in the myoepithelium and in the basement membrane (Figs. 7 and 8).

\section{PAS Reaction}

Control (Fig. 9)

The stainability of the glandular cells is extremely weak. The nucleus has no stainability at all, looking an empty hollow. In the cytoplasm, there are many irregular-sized granules, which give an intense positive reaction with the PAS. These granules are mostly 
localized in the portion of the cytoplasm upward from the nucleus, and are not found in the terminal extensions of each cell. These PAS positive granules may probably be the brown pigment granules, which are stained blue with thionin as described above. Even after being stained red with the PAS, the original brown tone can be observed. The general stainability with the PAS becomes a little weaker after being treated with diastase. The diminution of the stainability is too small to conclude the presence of an appreciable amount of glycogen in the cytoplasm or in the pigment granules. The myoepithelium is stained in the same intensity as the glandular cells. The basement membrane is intensely stained.

Injected animal (Figs. 10 and 11)

The PAS reaction in the portion of the cytoplasm of the glandular cell above its nucleus, diminishes. Sometimes the stainability of the terminal extension of the glandular cell is more intense than other parts of the cytoplasm. The red stained pigment granules, which are demonstrated in the control material, decrease and sometimes totally disappear. The pigment granules are not found in the lateral portion, but are demonstrated only in the upper portion of the cytoplasm from the nucleus.

The stainability of the myoepithelium is usually unchanged, although it is sometimes more intensified (Fig. 11). The basement membrane shows an unchanged stainability.

\section{Alkaline Phosphatase}

Control (Figs. 12 and 13)

The most intense activity of the alkaline phosphatase is seen in the nucleus of the glandular cells, and decreases in the order, in the cytoplasm and in the myoepithelium. Within the cytoplasm, beaded filaments, with indistinct contur, are demonstrated, which may probably be mitochondria. The activity on the boundary lines between glandular cells is usually intense. The pigment granules give no appreciable positive activity. The nuclear activity in the myoepithelium is intense. than in the glandular cells (Fig. 13); nevertheless, the cytoplasmic activity is 'sometimes hardly demonstrable. The basement membrane lacks the enzyme activity.

\section{Injected material (Figs. 14 and 15)}

The activity of the terminal portion is generally stronger than in 
the control. The cytoplasmic activity is particularly intense in the basal part and in the terminal extension. Sometimes the extremely deep coloration of the whole cytoplasm covers the picture of the cytoplasmic consistituents and makes it impossible to distinguish their finer structure from each other. Although the whole activity in the myoepithelium increases, the intensification of the stainability is not uniform, being intensified markedly in some places, and only slightly in other places. The basement membrane shows no remarkable change.

\section{Acid Phosphatase}

\section{Control (Figs. 16 and 17)}

The strongest enzyme activity in the glandular cell is found in the nucleolus, and the intensity of the activity gets weaker in the order, in the karyoplasm and in the cytoplasm. The nucleus of the myoepithelium is spindle-shaped and has an activity of the same intensity as that of the glandular cell. A fine network in its cytoplasm shows a positive reaction. The cytoplasmic activity is strongest in the upper part of the nucleus than in other parts, and it is extremely weak in the terminal extension of the cytoplasm. The basement membrane gives no positive reaction.

Injected animal (Fig. 18)

The enzyme activity of the glandular cells is generally intensified in the injected animals, .comparing with the results obtained in the control. The strongest activity is proved in the nucleus. The part of the cytoplasm above the nucleus shows an extremely intensified activity. No intensification of the activity is demonstrated in the myoepithelium, where only the nucleus gives a positive reaction as well as in the control. The basement membrane shows no activity.

\section{Discussion}

The presence of the secretion grannles in human apocrine sweat gland was demonstrated by $\mathrm{Nag}$ a mits u (1941), by Min a mitani (1941) and by I to (1949), and the details of the ripening process were clarified by these investigators. Os og o e (1951) carried out a similar observation on human cerminous gland. In the present study, the author could not demonstrate granules, which are stained blue with the Heidenhain's iron hematoxylin, but could prove the existence of a considerable amount of vacuoles, i. e. choromophobic secretion spherules, 
and these spherules are reduced by the administration of pilocarpine.

I to and I washige (1951) discovered that the yellow granules in human apocrine sweat glands stain blue with thionin. Despite their findings, the author found that the dark brown granules stain blue with the same dye. Althohgh the localization and the colour intensity are somewhat different, these granules have presumably a close kinship in their natures with one another. After the administration of pilocarpine injection, the basophilia of the cytoplasm with thionin diminishes, where as occasionally the basal part of the cytoplasm stains with thionin intensely reddish violet. This stainability probably means a picture of the preliminary process for the next coming secreting function.

The presence of glycogen in human apocrine sweat glands has been discussed by many investigators. Bunting, Wislocki and Dempsey (1948) denied the presence. I to and $\mathrm{O} t \mathrm{a}$ (1949), M o n t a g n a et al (1951) reported an occasional appearance of glycogen. Ot a (1950) stated that a small amount of glycogen is usually present. I to and I w a shige (1953) found that it lacks in material of advanced age. In the author's present study, although polysaccharide is demonstrated, yet the presence of glycogen is still doubtful. The pigment granules really give a positive PAS reaction, nevertheless this stainability certainly does not mean glycogen. The large pigment in human apocrine sweat glands is also reactive to the PAS method (Montag na, 1956). According to Shelly and Mescon (1952), the alkaline and the acid phosphatases in the human eccrine sweat gland increase their activities during perspiration. In spite of being apocrine, in the author's experiment, the activities of the gland cells are generally increasing. The fact, that the alkaline phosphatase activity is proved as being positive in the terminal extension of cytoplasm, and is intensified by the pilocarpine injection, is necessary to be reconsidered. The question, what is apocrine secretion requires further criticium. The intensification of the alkaline phosphatase activity in myoepithelium by the pilocarpine administration suggests an intimate relationship between the secretion and pilocarpine.

In human axillary apocrine gland, no phosphacise activity was demonstrated (Bunting et al., 1948). In dog and rabbit materials, only the apical border of the gland cell gives a positive reaction (Montag $\mathrm{na}, 1950$, Mont a $\mathrm{n}$ a and Park, 1948). FBesides, in the Gll. vestibulares nasi of cat, the activity is distinctly demonstrated, and its intensification by the pilocarpine injection is ascertained. These 
results mean probably that the difference exists when species or organs differ. It is stated by Montagna (1956): "Apocrine sweating is largely a response to the adrenergic stresses". However, the appearence of such a change after the pilocarpine injection as described above shows an intricacy of the pharmacological response of living organism.

\section{Summary}

The cat Gll. vestibulares nasi were investigated cytochemically. The changes caused by the subcutaneous injection of pilocarpine were observed. The presence of beaded mitochondria in glandular cells is ascertained, but their contour is not distinct. The terminal extension stains dark with iron hematoxylin.

The pilocarpine injection results in a decrease of the basophilia. Presumably glycogen does not exist in the glandular cell, or its amount is extremely small, if it is present. No remarkable changes is observed after the injection.

An intense alkaline phosphatase activity is seen in the the luminal side of the cytoplasm. The injection results in a general intensification of the activity, and a remarkable intensification is found in the myoepithelium.

An intense acid phosphatase activity is observed in the nucleus of the glandular cell. The injection causes a general intensification of the activity, and an especially intense activity is demonstrated in the luminal side of the cytoplasum.

\section{Acknowledgements}

The author's gratitude is due to Professor T. Taniguchi, M. D. for his encouragement and criticism. It is also a privilege to acknowledge the guidance of Instructor M. Ihnuma, M. D. who scheduled the whole project.

\section{References}

Bunting, H., Wislocki, G. B. and Dempsey, E. W. 1948. The chemical histology of human eccrine and apocrine sweat gland. Anat. Rec. 100:61.

Gom or i, G. 1952. Microscopic Histochemistry. The University of Chicago Press. I t o, T. 1949. Histology and cytology of sweat glands. Igakunoshinpo. 6:106 (in Japanese). 
I to, $\mathrm{T}$ and $\mathrm{Ota}$, R. 1949. Observation on the glycogen of sweat gland. Seitainokagaku. 1:146 (in Japanese).

It o, T., Tsuchiya, K. and I washige, K. 1951. Studien über die basophile Substanz (Ribonukleinsäure) in den Zellen der menschlichen Schweissdrüsen. Arch. hist. jap. 2: 279.

It o, T. and I w a s hi ge, K. 1953. Zytologische und histologische Untersuchungen über die apokrinen Achselschweissdrüsen von gesunden Menschen höheren Alters. Arch. hist. jap. 5: 455.

Maeda, M. 1954. Die vergleichend-histologische Untersuchung der sog. Gll. vestibulares nasi bei den Säugetieren. I. Mitteilung. Über das Vorkommen der Drüse und ihre Verteilung und Grösse. Fol. anat. jap. 25: 229.

M in a mitan i, K. 1941. Zytologische und histologische Untersuchungen der Schweissdrüsen in menschlicher Achselhaut. Über das Vorkommen der beson. deren Formen der apokrinen und ekkrinen Schweissdrüsen in der Achselhaut von Japanern. Fol. anat. jap. 20:563.

Mont a g n a, W. and Park, H.F. 1948. A histochemical study of the glands of the anal sac of the dog. Anat. Rec. 100: 297.

Montagna, W. 1950. The brown inguinal glands of the rabbit. Am. J. Anat. 87: 213 .

Mont a g n a, W., Chase, H. B. and Hamilt on, J.B. 1951. The distribution of glycogen and lipids in human skin. J. Invest. Dermatol. 17: 147.

Mon ta g n a, W. 1956. The structure and function of skin. Academic Press Inc. Pub. New York.

Na g a mit s u, G. 1941. Histopathological studies on osmidrosis. Keio-igaku. 21: 1011 (in Japanese).

$\mathrm{O} t \mathrm{a}, \mathrm{R} .1950$. Zytologische und histologische Untersuchungen der apokrinen Schweissdrüsen in den normalen, keinen Achselgeruch (Osmidrosis axillae) gebenden Achselhäuten von Japanern. Arch. hist. jap. 1: 285.

O s o g o e, S, 1951. Zytologische Untersuchungen der Gl. ceruminosa. Arch. hist. jap. 2: 153.

She $11 \mathrm{y}$, W. B. and Mescon, H. 1952. Histochemical demonstration of secretory activity in human eccrine sweat glands.

J. Invest. Dermatol. 18: 289.

\section{Explanation of Figures}

Figs. 1 and 2. control, Levi, iron hematoxylin stain.

Figs. 3 and 4. injected animal, Levi, iron hematoxylin.

Figs. 5 and 6. control, thionin stain.

Figs. 7 and 8. injected animal, thionin stain.

Fig. 9. control, PAS reaction.

Figs. 10 and 11. injected animal, PAS reaction.

Figs. 12 and 13. control, alkaline phosphatase.

Figs. 14 and 15. injected animal, alkaline phosphatase.

Fig. 16. control, acid phosphatase.

Fig. 17. in jected animal, acid phosphatase. 
Plate 1
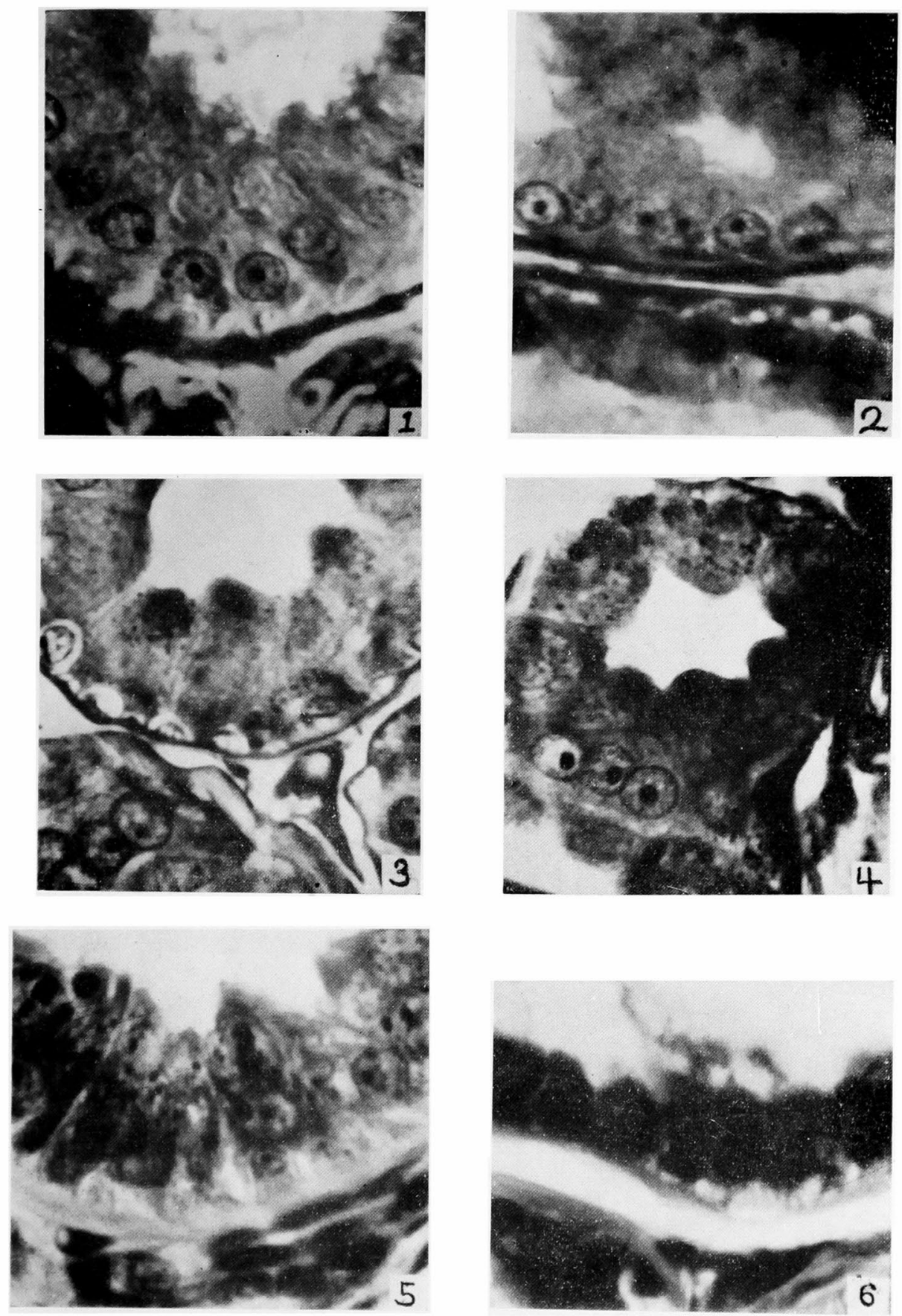

K. Takamt ra 
Plate II
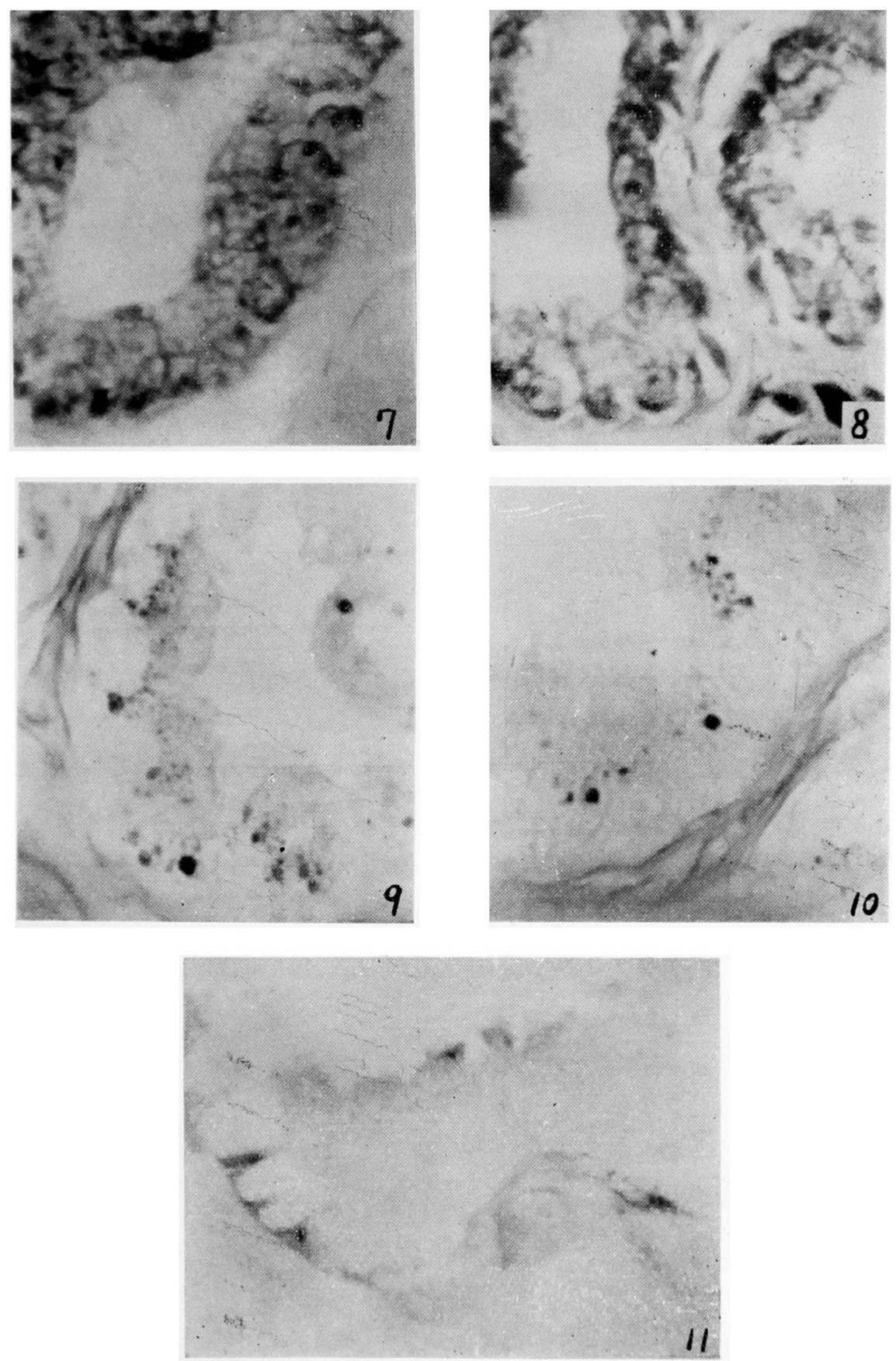

K. Takamura 
Plate III
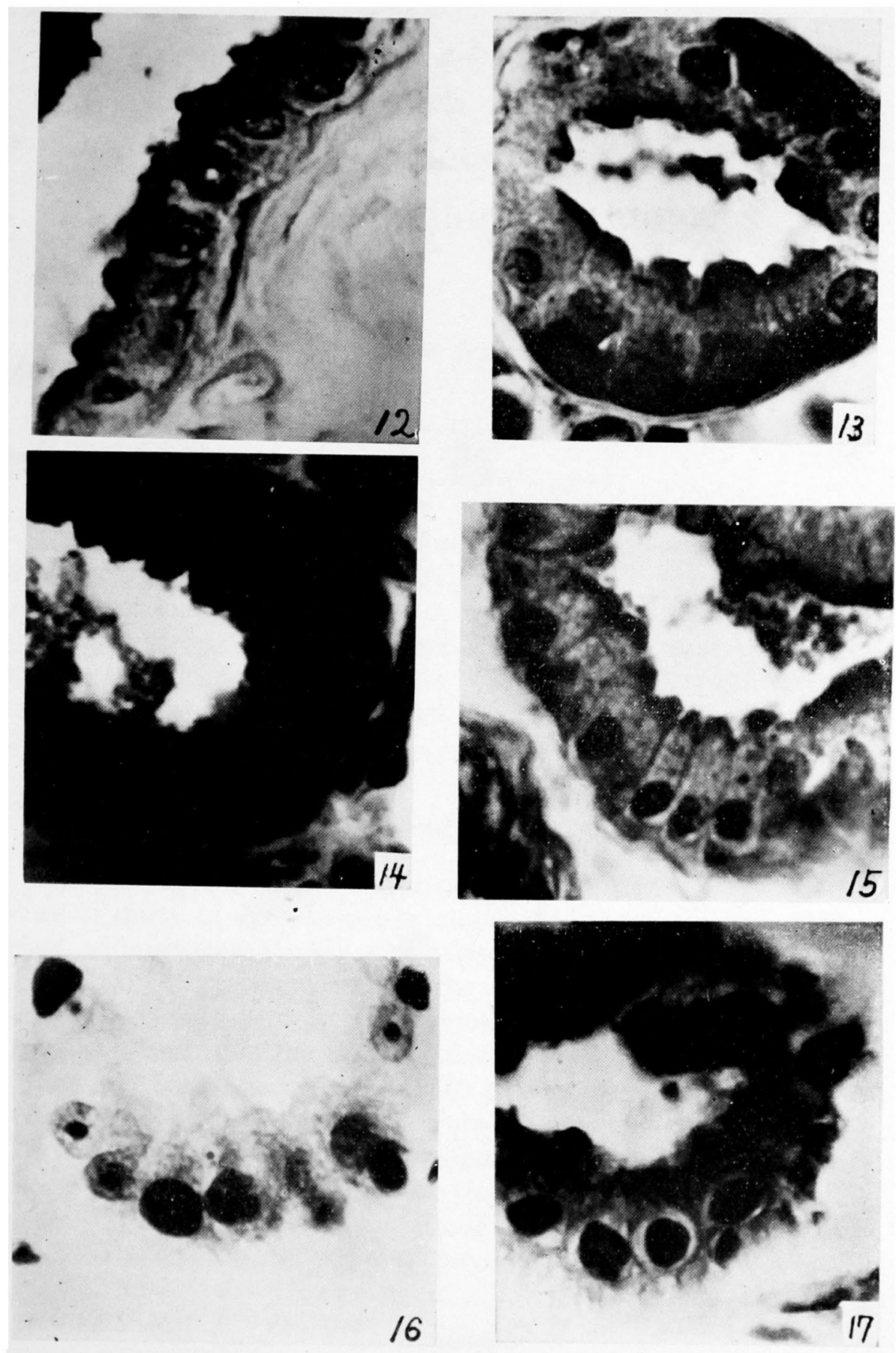

K. Takamura

16 